\title{
Guidelines for the submission of manuscripts
}

\author{
Dr. Peter Foot
}

The CONNECTIONS Journal welcomes the submission of manuscripts on topics of broad significance to the security community across the Euro-Atlantic Partnership, including, but not limited to, security and defense policy, regional issues, strategic matters, doctrine, operations, force structures, the application of technology, professional military education and training, military ethics, military history, and leadership. Forward-looking pieces which present original concepts or ideas, new approaches to old problems and fresh interpretation are especially welcome.

\section{Authors are asked to note the following general guidelines}

Manuscripts may be submitted in either English or Russian.

As a general rule, manuscripts of major articles should be between 3500 to 7500 words in length, including endnotes. However, shorter pieces are also welcomed, especially views and opinions that engage in the debate of relevant issues, as are letters to the editor.

Manuscripts must be submitted in electronic format, on disc or by e-mail, in MS Word97 or later versions. E-mail address pfpconsortium@ marshallcenter.org.

Manuscripts should be accompanied by appropriate graphs, charts, or other illustrations which illuminate the context of the article. Graphs, charts, etc should not be embedded in the manuscript, but should be saved as separate documents. At the present time, maps and photographs are problematic; contact the Consortium for advice.

Manuscripts should conform to standard academic style, using either standard American English spelling or Russian spelling, with footnotes rather than endnotes or the 'Harvard' system.

Acronyms and military abbreviations may be used in the body of the text provided that the term is written out in full the first time it is used, followed by the abbreviated form in brackets. On the other hand, military jargon and slang terms should, as a rule, be avoided.

All submissions must be accompanied by a brief (one paragraph) biographical sketch of the author that includes current appointment, telephone number, e-mail address and mailing address

All manuscripts will be reviewed anonymously by at least two external readers from the Editorial Board, who will make recommendations to the Editors as to suitability for publication. Manuscripts will be judged on the originality and quality of the argument or discussion, the relevance and timeliness of the topic, and on quality of the writing style 


\section{THE QUARTERLY JOURNAL}

The Editors reserves the right to edit manuscripts for style, grammar and length, but will not make editorial changes which affect the integrity of the argument or discussion without reference to the author. Manuscripts that are not accepted for publication will be returned to the author. No copy of unpublished manuscripts will be retained by the PfP Consortium or its Editorial Board. 